\title{
The problem of developing the experience of self-determination of adolescents in the process of socialization
}

\author{
Irina Wagner ${ }^{1, *}$ \\ ${ }^{1}$ Institute for Childhood Studying, Family and Socialization of the Russian Academy of Education, \\ 105062, 5/16 Makarenko str., Moscow, Russia
}

\begin{abstract}
The article continues a series of author's publications on the formation of personal socio-cultural experience of children and adolescents in the process of education and socialization, which determines the formation of the teenager's personal position. We consider one of the types of personal socio-cultural experience of adolescents, namely the experience of behavior in situations of choice, making independent decisions, which is crucial in preparing students for life self-determination in all its aspects. The conditions created in the educational organizations for realization by teenagers of independent choice, an opportunity of acceptance by teenagers of independent decisions are studied. The results of the analysis of school documentation and teachers' views on the significance of the experience of self-determination of adolescents, typical situations of uncertainty, are based on the results of the survey. A conclusion is drawn on the need to design a space for self-determination of adolescents in an educational organization and to implement technologies for the pedagogical support of adolescents in situations of choice.
\end{abstract}

The development of personal socio-cultural experiences of adolescents is regarded as one of the most important goals and results of the processes of upbringing and socialization, since it determines the character of the teenager's personal position [1,2].

In the context of the priorities of modern education oriented towards democratic values and the preparation of schoolchildren for self-determination, special attention is required by the experience of adolescent behavior in situations of uncertainty, the experience of making independent decisions in the situations of choice.

Are there spaces for self-determination of adolescents in the modern school? Are they given the opportunity to make independent decisions? How important is the task for teachers to develop the experience of adolescents in the experience of self-determination? These and similar questions we set ourselves in the course of research on the problem of developing the experience of self-determination in adolescents.

We analyzed the materials of the activities of general education institutions, aimed at identifying the situations of choice, self-determination, which are created for students in the educational process. We analyzed the information presented on school websites, including

* Corresponding author: wagner.forschungen@gmail.com 
the concepts of the development of educational institutions, educational programs, information on educational work, the activities of supplementary education centers, children's public organizations, school activities, etc. The working documentation includes 212 general education institutions (128 urban and 84 rural), placed on their websites from 20 subjects of the Russian Federation.

The analysis shows that in the framework of the training and educational process, modern students are faced with the following choice situation: (1) the selection of items for in-depth study, exam, elective or additional educational programs (training courses) - that is the choice in the "educational and professional self-determination," these choices are provided, as a rule, by the educational programs being created by the majority of educational institutions, especially those developing practical skills; (2) the choice of additional education programs and leisure activities, projects - the choice of leisure activities is more likely to be guessed than documented: at least half of the school websites studied are given, for example, information about the circles, sections, creative associations; it is obvious that adolescents can engage in them on a voluntary basis; (3) it can be assumed that there are situations of choice related to the activities of school authorities (28\% of school Internet sites have information on their activities); (4) $7 \%$ of the sites being studied contain information on the activities of children's public organizations; profile associations have opportunities for adolescents to select types and forms of activity, roles in project groups, etc.

Our research goal was to identify and characterize the types of problem situations and situations of uncertainty in which adolescents experience self-determination. All types of situations that we listed above have not only differences, but also general properties: they are all pedagogically organized and implemented within the educational process; it is these situations that are to be projected in the framework of models for the education, upbringing and socialization of adolescents, namely they have the potential for forming competences in decision-making in adolescents, the implementation of which can ensure their positive socialization. Whether this potential will be realized depends to a large extent on the position of the teacher, on the extent to which the educational system of the school is imbued with humanistic, democratic values, how management is implemented, and the interaction of teachers and students. We conducted surveys of teachers who had a dual focus: on the one hand, to look at the situation of uncertainty arising in the process of socialization of adolescents; on the other hand, to reveal the position of teachers in relation to situations of self-determination of adolescents and take it into account in developing technologies for pedagogical support of adolescents situations of choice. Let's present some results of the study.

The task of forming adolescents' readiness to make decisions in the choice situations is considered relevant along with other tasks by $58 \%$ of the respondents. As the most important task, it is allocated $16 \%$. And another $26 \%$ are not ready to classify this task as topical. Even more clearly the position of teachers in relation to situations of children's self-determination is manifested in the answer to the following question "How much is the situation of choice present in the life of adolescents 12-15 years old and how important are their decisions?"

The results are as follows. 50\% of respondents (let's call them the first group) do not attach serious importance to the decisions of adolescents. They believe that all or almost all solve adults ( $42 \%$ of respondents in the first group); that, at best, adults consult teenagers in making decisions related to their activities (also $42 \%$ of the respondents in the first group) and $16 \%$ of the respondents in the first group suggest that adolescents are possible and make some decisions independently, but the significance of these decisions is still small. $30 \%$ of respondents (let's call them the second group) believe that in the life of adolescents there are choices, and although adolescents do not have a decisive say, these situations are 
important for their socialization. $20 \%$ of respondents (let's call them the third group) believe that adolescents make many independent decisions, some decisions affect their lives for a long time ( $45 \%$ of respondents in the third group); that there are a lot of situations in the life of adolescents, and the decisions that adolescents take are very important and responsible; more than that, much depends on them in their lives for years $(55 \%$ of the respondents in the third group).

Thus, we see that $80 \%$ of teachers (respondents of the first and second groups) believe that adolescents do not have a decisive word in the choice situations, they do not consider it possible to trust them with vital decisions, allowing independence only in "small things," i.e. which can be seen by adolescents as problematic, the situations of uncertainty they are experiencing can be assessed by teachers as having no significance. Only $20 \%$ of teachers recognize the importance of independent decisions of adolescents and see a variety of problem situations and situations of uncertainty that they have to solve in the process of socialization.

Next, we tried to identify some types of problem situations and suggested that teachers assess their significance, thereby building a rating of problem situations and situations of uncertainty in the process of socialization of adolescents. The result is as follows: the 1st place - situations of choice in interpersonal relations with peers (decisions related to maintaining or destroying friendly relations, behavior in conflict situations, etc.); the $2^{\text {nd }}$ place - the situation of choice associated with the organization of free time (the choice of types of employment, conditions, etc.); the 3rd place - the situation of choice associated with the danger of familiarizing with harmful habits (smoking, alcoholism, drugs, etc.); 4th place - the situation of value self-determination (which tasks of life should be given the highest priority, which should be abandoned, which values should be followed); 5th place the choice situations related to the content of education (what subject to study, at what level to master a particular subject, etc.); the 6th place - the situation of choice associated with making money and spending (with the difference in points between each stage of the rating was about the same value, only the 6th place was significantly outperformed). It is characteristic that when answering this question, teachers did not deny the existence of these types of problem situations in the process of socialization of adolescents, which, once again, emphasizes the low importance of decisions made by adolescents in the eyes of respondents, the inattention of teachers to independent decisions of adolescents, the formation of their readiness for self-determination, competence in decision-making in problem situations.

In an effort to actualize the experience of professional work of teachers in the context of our research tasks, we proposed to recreate some situations in persons, i.e. to give examples of independent solutions of adolescents known to teachers from their own practice. Let's give examples on the most characteristic solutions illustrating the teachers' vision of the problem, structuring the types of situations by their content or sphere of life activity.

1. Situations associated with building a further educational and professional route: independent choice of profession contrary to the wishes of parents (Gosha, 17); the situation of making decisions about further education is a high school or a secondary specialized educational institution (Maria, 15; Anna, 16); the decision after the 8th grade to enter the cadet corps (Ivan, 15); the decision to enroll after 9th grade in college contrary to the wishes of the parents (Xenia, 9th grade); independent choice of the institute (Ilya, 11th grade); entrance to the art school for continuing professional education (Maria, 15).

2. Situations associated with the choice of types of additional education or leisure activities, the performance of organizational functions on its own initiative: an independent decision to draw, attend an art school (Elena, 13 years); decision to improve knowledge of the Russian language and mathematics (Masha, Serezha, 8th grade); independent choice of leisure activities, such as sports dancing (Marina, 15); independent choice of learning 
Chinese instead of a European language (Olga, 17); the decision to organize holidays for the whole class (Dasha, Lena, Tanya, 8th grade); choice of hobbies (Egor, 15); the situation related to the choice between school sections (Andrei, 14); an independent choice of the program and preparation of congratulations for the boys on February 23 (Anna, 12); holding a charity fair (Asya, 16 years old); self-preparation of the concert scenario by March 8 (Lana, 14).

3. Situations related to conflict resolution; interpersonal relations: with the whole class refused to fight with another student in a conflict situation (Vsevolod, 7th grade); decision to end friendly relations with a classmate (Zhenya, 13); after another disassembly with a classmate decided to hide this case and to agree independently with him that the beating of the boy did not reach the teacher, parents (Igor, 14).

4. Situations related to overcoming bad habits, choice in favor of a healthy lifestyle: an independent decision to never take up a cigarette, probably because of the negative experience of monitoring smokers (Gulya, 14); decision to lead a healthy lifestyle despite the environment and temptations (Ivan, 15); the decision to quit smoking and boxing, although he smoked from the 3rd grade (Yuri, 15); expressed a desire to fight with smokers at school (Sasha, 13); the decision to go in for sports, go to the gym (Arseniy, 16 years old).

5. Situations of choice in the family space: the situation of choosing when parents are divorced, choosing with whom to stay (Christina, 16); the boy brought a homeless puppy to the house was only one who cared (Sasha, 13). The next category of situations also focuses on the choice that often occurs also in the space of the family.

6 . The situation of choice associated with earning or spending money: the money earned on the distribution of advertising gave the parents an opportunity to buy a big thing (Anya, 14); the teenager, without asking his parents, took a large amount of money and bought himself and a friend a toy plane for 5 thousand roubles (Mels, 14); the decision to start working after the 10th grade (after the death of her father), and a year later she began to study in the 11th grade externally (Ekaterina, 16); the decision to work in the school labor brigade and a choice of spending the money earned there (Alexander, 15); decision to work (for salary) in the summer period (Alex, 14).

As we see, the results are sometimes contradictory: it was shown above that the situations connected with making decisions about spending or making money ranked last in importance; and when it became necessary to recall specific adolescents and decisions made by them, it turned out that situations involving money were one of the six independent groups of situations, cited as examples. Attention is drawn to a few more points. As examples, not only positive, but also independent mistaken solutions are given; although, in general, the disclosure of the ability of adolescents to independent productive solutions dominates. The ability of adolescents to make independent decisions becomes apparent to adults often in the event that the decision contradicts the position of adults. Among the examples of decisions taken, there was not one that concerned the choice in the educational process in the school - those situations that are listed in the next question. In addition, it should be noted that examples were given only in $35 \%$ of cases, and $65 \%$ of teachers were not ready for a short time allocated for the survey, recalling the independent decisions of the pupils.

In more detail, the situation of choice in the educational process allows us to consider the analysis of the answers to the following question: "Do adolescents have a choice situation and the possibility of making independent decisions in the learning process? If so, which ones?." We received the following ranking of the choice situations in the educational process: the 1st place took 2 positions: (a) adolescents can choose where and how to improve their knowledge of the subject (in school or outside school, for example, at a university), and (b) they can choose electives; the 2nd place - an opportunity to choose additional education programs; the 3rd place has 2 positions: (a) the opportunity to choose topics for individual projects in all 
subjects and (b) to choose which class to study; the 4th place - 2 positions: (a) the choice of the academic disciplines (in the senior classes) and (b) the choice of the subject level.

The opportunity to choose and make independent decisions within the programs of extracurricular / extracurricular educational work was assessed by the teachers as follows: the 1st place - the opportunity to choose the events in which to participate; the 2nd place the opportunity to choose their roles in collective creative activity; the 3rd place - an opportunity to choose the themes of creative projects; the 4th place -2 positions: the opportunity to choose (a) the content of their activities in the framework of ongoing activities and (b) in which creative associations to participate.

What are the attitudes of teachers about the preparation of schoolchildren for selfdetermination that determines the actual practice of organizing the process of socialization, which settings are implemented in real practice in most cases? The rating of such facilities teachers were built during the survey. The 1st place took 2 positions, emphasizing the urgency and priority of the following tasks: (a) "Preparing for self-determination is a priority goal of educational work and the efforts of teachers are aimed at creating this space of self-determination"; b) "Preparing for self-determination occurs every day, it is the behavior issues in the choice situations that are discussed with adolescents most often" (as we recall, when answering the first question, this position was not as strong as at the end of the work, which is connected with a detailed analysis situations of choice, turning to one's own practice, immersing in a topic. The second place is occupied by the following attitude: preparing for self-determination is a matter of preventing bad habits, the efforts of teachers are aimed primarily at ensuring that the child himself can say "drug use," "smoking," etc. The third place is occupied by the following statement: "Teens have little experience in life, it is better to tell them how to act, even if it is a school wall newspaper - better to help them in time and work with them, so that the final the result would be better." The 4 place is occupied by 2 settings: (1) "Adults play the real responsibility for all decisions of adolescents, so all self-determination in adolescence is more a game, an illusion than a real choice" and (2) "Preparing for self-determination while going on in the game, all responsible decisions are made by adults, and children are preparing to make independent decisions in game situations." The 5th place was taken by, with a noticeable gap from the previous ones, the following position: "Preparing for self-determination is a common goal, rather a theory that is not applicable to real practice."

Considering some inconsistency of the positions expressed by the teachers, let us turn to their reflections on how to ensure the preparation of adolescents 12 to 15 years old for making independent decisions in the situations of choice. How would you solve this problem? How would the pedagogical process be organized? What would change in the existing traditions of teaching and educational work? What components would the program of your pedagogical actions consist of? What recommendations would you give to your colleagues? ... Let's give examples of judgments of teachers on topic of the study: "only together with the family, work with parents"; "Give the advice to high school students to use the opportunity to supplement the necessary list of such events with those that excite them; to help them in the preparation and implementation of these activities"; "Interaction of the Council of senior pupils with the administration is carried out directly at joint meetings' "Assist children in the successful implementation of their ideas"; "The teacher is the innovator of ideas. The teacher is an active participant in the events. The teacher is an assistant, coordinator in the process of action. The teacher is a good listener and interlocutor of the child. The teacher is a positive appraiser. The teacher is a skilled critic"; "To give more freedom to students so that they feel full responsibility for decisions made by them; "On life examples that relate to students, to show how to act, and next time to make their own decisions independently, when analyzing works in literature lessons, give the right of choice to students, how they would act in such a situation"; "Strengthen school self-government, 
make it real and effective. In the program, independence should be purposefully brought up in all classes. Incorporate self-determination into the work of parents' universities"; "To teach, to tell how to act properly, leaving the choice for a student. It is more common to discuss different situations, to look for the right solution. Trust the case and see the result, discuss, point out the mistakes"; "To spend more class hours devoted to this problem."

In general, it is obvious that the implementation of the humanistic approach, democratic values, the preparation of schoolchildren for self-determination remains difficult to solve in practice, that the "problem" situations are called by those teachers who are those from the point of view of adults, and not those that determine the level of anxiety of adolescents or character of their personal position. At the same time, it is gratifying that a significant part of educators are aware of the need existing in adolescents to have experience of selfdetermination, making independent decisions, and expressing their readiness to provide them with a choice. The study actualizes the need to design the space for self-determination of adolescents in the educational organization, the special training of teachers for the development of adolescents' experience of self-determination and methodological support of their activities in the pedagogical support of adolescents in situations of choice.

\section{References}

1. I. V. Wagner, Bulletin of the Tomsk State Pedagogical University, 1, 190 (2018)

2. I. V. Wagner, Professional project: ideas, technologies, results, 1 (2011) 